\title{
A case of Sinus Histiocytosis with Massive Lymphadenopathy (Rosai-Dorfman Syndrome) from Western India
}

\author{
Priyanka A. Jani and Deepa Banjan
}

KEYWORDS: Rosai-Dorfman Syndrome, Histiocytosis, Emperipolesis, Lymphadenopathy, Ascaris

\section{INTRODUCTION}

Sinus histiocytosis with massive lymphadenopathy, also known as Rosai-Dorfman Syndrome, a nonmalignant variant of histiocytosis (1) is a chronic reactive disorder. It presents as a benign, chronic, massive enlargement of cervical lymph nodes (LN) accompanied by fever, leukocytosis, elevated erythrocyte sedimentation rate (ESR) and hyperglobulinamia (2). There is no malignant proliferation of the class II histiocytes (i.e. normal macrophages and monocytes).

The etiology of this disease is currently unclear. Sinus histiocytosis with massive lymphadenopathy may be of two types - either familial or infection induced (2). With respect to the latter, increased antibody titers to Epstein Barr and measles viruses have been observed; however, etiological evidence is lacking (1). Immune disturbances are likely to be a feature in some patients. Subtle undefined immunological defects are also considered as a causal factor. Human Herpes Virus6 DNA has been detected in biopsy specimens and is considered as a contributing factor (6).

Sinuous histiocytosis with massive lymphadenopathy (SHML) most frequently occurs in first and second decades of life, with a peak incidence at twenty years of age (1). There is a higher prevalence in males, and

*To whom correspondence should be addressed:

Dr.Priyanka A. Jani

Selmeston Court, Augusta Street

Grimsby

North East Lincolnshire

United Kingdom

DN34 4TB

Telephone: 00447988787951

Email: dpajjani@yahoo.com among Afro-Caribbeans as compared to Caucasians and Asians. Also, a familial association has been observed in some cases (3).

\section{CASE}

A twelve years-old Indian girl residing in Maharashtra, Western India, presented with bilaterally symmetrical lymphadenopathy with a "bull neck" appearance of three years duration.

Three years prior to presentation, the patient developed a small reddish papule, which gradually increased in size. The patient noticed enlargement of glands initially on the site of the papule and then bilaterally. Lymph nodes were discreet, mobile, nontender, non-matted, and about $2-4 \mathrm{~cm}$ in diameter. A primary biopsy of cervical LN showed non-specific lymphadenopathy with sinus histiocytosis. There was no history of fever, upper respiratory tract disease, dental caries or viral infections. No constitutional symptoms were suggestive of malignancy. No other organ involvement was documented.

The neck swellings regressed over 7-8 months. However they did not disappear completely. Symptomatic treatment was offered by the physician.

One year later, in 2002, the patient presented with increase in cervical swellings along with bilateral solid axillary swellings. Swellings were tender, solid, non matted, mobile and preceded by fever. The second cervical LN biopsy revealed histiocytic lymphadenopathy and dilated sinuses filled with histiocytes. The supporting investigations are shown in Table 1. This table shows prominent eosinophilia with mild normochromic anemia.

The patient again presented after three years with a 

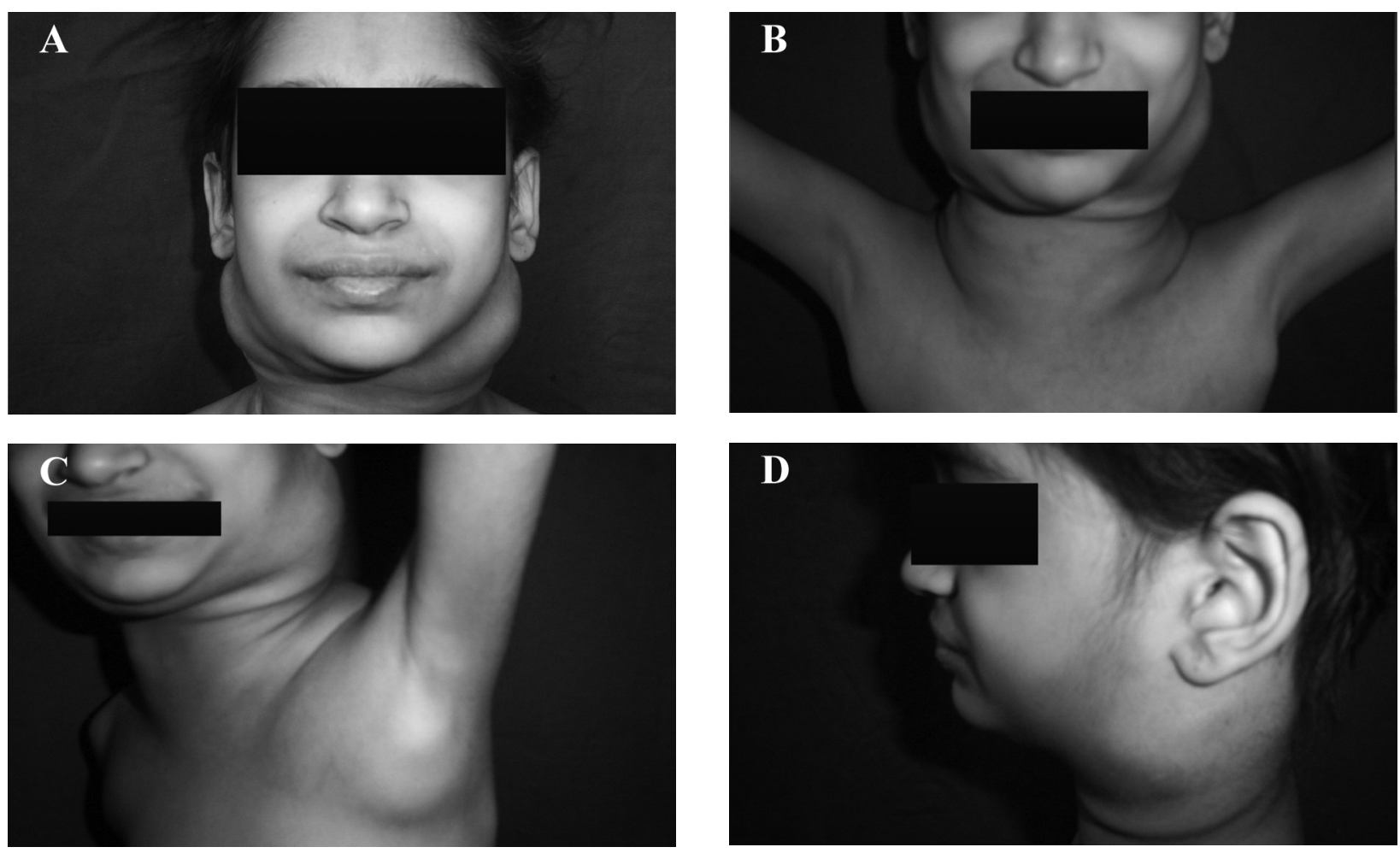

Figure 1. (a) bilateral cervical swelling, (b) bilateral cervical and axillary LN enlargement, (c) left axillary nodal enlargement, and (d) left cervical LN enlargement.

third episode of glandular proliferation mainly involving bilateral cervical LN. Clinical findings included bilateral tender enlarged cervical lymph nodes, fever, ascites, and pedal edema. The investigations done this time (Table $1 ; 2004)$ showed anemia, hypoproteinemia, and low serum iron levels. The ESR remained low with no immunological or histopathological cause for lymphadenopathy found.

The lymphadenopathy was stated to be non-malignant on three repeated biopsies and no malignant advancement was noted over the period of three years. An ultrasound showed multiple LN involvement with mild hepatosplenomegaly. Other causes of cervical lymphadenopathy like tuberculosis, sarcoidosis, Epstein Barr virus, hepatitis virus, HIV, autoimmune disease have been ruled out by performing specific tests. Malignant potential has also been negated by absence of supportive clinical evidence.

Other vital parameters of the patient remained stable throughout the span of three years. The patient had not attained menarche. Bowel and bladder habits were normal, sleep and appetite adequate. There was no history of any drug or alcohol intake. The family history was negative for episodes of any such disorder.

\section{COURSE AFTER ADMISSION}

The patient had severe anemia, hypoproteinamia and eosinophilia. Stool examination showed eggs of ascaris, which could account for the eosinophilia.

Patient was given standard treatment with pyrantel palmoate $20-25 \mathrm{mg} / \mathrm{kg} /$ day and mebendazole $100 \mathrm{mg}$ bid for three days, which lead to expulsion of fully grown 15-20 adult round worms in the feces.

A regression in the size of the cervical $\mathrm{LN}$ and systemic involvement (i.e. hepatosplenomegaly) was seen over 2 weeks post-treatment. There was significant decrease in the cervical LN size. The abdominal symptoms and presence of ascites and pedal edema regressed after treatment of anemia. This regression in cervical LN following deworming points towards the probability of ascaris antigen acting as a trigger factor to the basic underlying hyper immunogenic status of the patient. However, no documented evidence for the same has been found.

The patient was discharged from the wards following significant cervical LN regression. She was continued on haematinics and was counseled well about the nonprogressive, benign nature of the sinus histiocytosis. 
Table 1. Investigations

\begin{tabular}{|c|c|}
\hline Investigations & Results/Comments \\
\hline \multicolumn{2}{|l|}{ September 2001: } \\
\hline Hemoglobin & $9.6 \mathrm{gm} \%$ \\
\hline Leukocytes & $18,000 / \mathrm{cm}^{2}$ \\
\hline Neutrophils & $70 \%$ \\
\hline Eosinophils & 12\%: Significant eosinophilia. \\
\hline ESR & $35 \mathrm{~mm} / \mathrm{hr}$ : Elevated ESR \\
\hline $\begin{array}{l}\text { Right cervical lymph node } \\
\text { biopsy }\end{array}$ & $\begin{array}{l}\text { Sinus histiocytosis with non } \\
\text { specific lymphadenitis. }\end{array}$ \\
\hline \multicolumn{2}{|l|}{ December 2002} \\
\hline Hemoglobin & $9.5 \mathrm{gm} \%$ \\
\hline Leukocytes & $21,000 / \mathrm{cm}^{2}:$ Leukocytosis \\
\hline Eosinophils & 12\%: Marked eosinophilia \\
\hline Random blood glucose & $80.5 \mathrm{gm} \%$, Normal \\
\hline Blood urea nitrogen & $8.6 \mathrm{mg} \%$ Normal \\
\hline Serum creatinine & $0.63 \quad$ Normal \\
\hline Uric acid & 4.2 Normal \\
\hline Chest X-ray & No abnormalities seen. \\
\hline \multicolumn{2}{|l|}{ Ultrasound abdomen/pelvis } \\
\hline Liver & $\begin{array}{l}\text { Mild hepatomegaly.normal } \\
\text { echotexture.no focal lesion.liver } \\
\text { span- } 13 \mathrm{cms} \text {. }\end{array}$ \\
\hline Abdominal LN & $\begin{array}{l}\text { Pre and Para aortic lymph nodes } \\
\text { seen.largest LN-18mm. }\end{array}$ \\
\hline $\begin{array}{l}\text { Cervical LN biopsy (April } \\
\text { 2002) }\end{array}$ & Histiocytic lymphadenitis \\
\hline $\begin{array}{l}\text { Cervical LN biopsy (Tata } \\
\text { Memorial Hospital, Dec } \\
\text { 2002) }\end{array}$ & $\begin{array}{l}\text { Dilated sinuses with histiocytic } \\
\text { proliferation and } \\
\text { lymphophagocytosis. Evidence } \\
\text { of sinus histiocytosis with } \\
\text { massive lympadenopathy. } \\
\text { Diagnosis of Rosai-Dorfman } \\
\text { Syndrome. }\end{array}$ \\
\hline Bone marrow biopsy & $\begin{array}{l}\text { Normocellular marrow showing } \\
\text { normal maturation of all cells. }\end{array}$ \\
\hline \multicolumn{2}{|l|}{ February 2004} \\
\hline Hemoglobin & $3.6 \mathrm{gm} \%$ \\
\hline Leukocytes & $16,100 / \mathrm{cmm}$ leucocytosis \\
\hline Serum total protein & 5.4 \\
\hline Serum albumin & 2.3 \\
\hline Serum globulin & 3.1 \\
\hline Blood urea nitrogen & 10.8 \\
\hline Ultrasound- abdomen & $\begin{array}{l}\text { Mild ascites, multiple peri- } \\
\text { pancreatic, para-portal enlarged } \\
\text { LN. Liver normal }\end{array}$ \\
\hline \multicolumn{2}{|l|}{$\begin{array}{l}\text { Specific investigations } \\
\text { Sept } 2001\end{array}$} \\
\hline Mantoux test & Negative \\
\hline $\begin{array}{l}\text { Antibody test for infectious } \\
\text { mononucleosis }\end{array}$ & Non reactive \\
\hline HIV test & Non reactive \\
\hline Australia antigen & Negative \\
\hline Anti-dsDNA antibody & Negative \\
\hline Antinuclear antibody & Negative \\
\hline
\end{tabular}

The family was also educated about the disease. She now attends the outpatient department for follow up at 1 month intervals and to date shows no reversal to previous symptoms.

\section{DISCUSSION}

\section{A) Histopathological features}

In sinus histiocytosis, there is a progressive filling up of the LN sinuses with normal histiocytes and lymphocytes. The histiocytes in SHML are S100 positive and CD1 negative (2). The constant feature on histology, 'emperipolesis' or lymphophagocytosis', is the presence of intact lymphocytes within the cytoplasm of histiocytes. This is of great diagnostic significance (3). Pericapsular fibrosis and inflammation are also seen. Ultrastructurally, histiocytes in SHML lack Birbeck granules and viral particles (3).

\section{B) Clinical features}

More than $90 \%$ of the patients with SHML present with massive bilateral, mobile, and non tender cervical lymphadenopathy (2). These nodes may at times be matted and prominent by periportal fibrosis. Forty percent of the cases may show extra nodal involvement. Soft tissues, generally eyelids, orbits and ocular adnexa, skin and subcutaneous tissue, gastro-intestinal tract, upper respiratory tract and central nervous system can also be involved. Low-grade fever is generally present along with mild, normochromic anemia (3), elevated ESR, leukocytosis, and hyperglobulinemia.

\section{C) Diagnosis}

In our case, there are a few characteristics that point to the diagnosis of sinus histiocytosis: 1) Clinical presentation of exclusive involvement and massive enlargement of cervical LN followed by axillary LN and abdominal LN. 2) Histopathological picture of dilated LN sinuses filled with histiocytes showing evidence of emperipolesis and absence of Birbeck granules. 3) Exclusion of the other differential.

\section{D) Progression}

The prognosis is excellent in most cases. Complete spontaneous regression is known to occur (3). The course of disease however may be protracted over three to nine months. Only two cases of progression, one to malignant lymphoma and another to amyloidosis have been documented (2).

E) Complications

Complications are mostly due to the pressure effects exerted by the enlarged cervical LN (1). Extensive disease may lead to complications due to 
immunological abnormality that may be present (3).

F) Treatment

No standard treatment for SHML is known. Corticosteroids and radiotherapy usage have been documented. Steroids in low doses can be used when there are compression symptoms or in presence of bull neck. Radiation is best avoided since it may result in hypothyroidism or malignant transformation of the preexisting benign condition (6). SHML is a generally benign condition with no significant malignant potential, which argues against the use of aggressive immunosuppressant therapy.

\section{CONCLUSION}

We have presented a case study with clinical and histopathological evidence pointing to the diagnosis of SHML or Rosai Dorfman syndrome. The patient presented with atypical features of anemia, accompanied by ascaris infestation. Following treatment of the parasite, there was significant regression of the size of the cervical LN and improvement in clinical condition.

The underlining immunogenic defects and the cause/environmental trigger factor (ascaris in this case) remain to be fully elucidated.

\section{REFERENCES:}

1. Weatherall, DJ. Disorders of blood. In: Oxford Textbook Of Medicine Volume 3, 4th ed, UK; 1996. p. 2610, 3604, 3610

2. Nathen D, Oski, F. Lymphohistiocytic Disorders. In: Haematology of Infancy and Childhood. Volume 2, 4th ed, Philedelphia; 1992: 1364

3. Rosai, J. Bone Marrow. In: Ackerman's Surgical Pathology Volume 2, 7th ed, USA; 1989. p. 1297

4. Forfar, Arneil. Oncology and Terminal care. In: Textbook Of Paediatrics, 5th ed, UK; 1998. p. 926

6. Levine PH, Jahan N, Murari P, Manak M, Jaffe ES. Detection of human herpesvirus 6 in tissues involved by sinus histiocytosis with massive lymphadenopathy (Rosai-Dorfman disease). J Infect Dis 1992; 166: 291-295.

Priyanka A. Jani (MBBS) is currently training in General Surgery with special interests in Vascular Surgery in the Yorkshire School of Surgery of the Diana Princess of Wales Hospital, Grimsby, UK . He is pursuing a Masters degree in Surgery.

Deepa Banjan (MBBS, MD) is a practicing Medical Consultant at the Rajiv Gandhi Teaching Medical College, India. She has carried out a thesis in Medicine and is currently pursuing special interests in Infectious Diseases. 